Seção Temática: Os Recursos Públicos em Disputa

Volume 11 - $2021 \mid$ n. 22

\title{
Financiamento Estudantil Público e a Expansão do Ensino Superior Privado no Brasil: o caso da Rede Wyden Educacional ${ }^{1}$
}

\author{
Samantha Castro Vieira de Souza \\ Universidade Federal do Pará (UFPA), Belém/PA - Brasil \\ Vera Lucia Jacob Chaves \\ Universidade Federal do Pará (UFPA), Belém/PA - Brasil
}

\section{Resumo}

Este trabalho tem como objetivo analisar o financiamento estudantil público via FIES e ProUni e seu impacto na expansão do ensino superior privado no Brasil, em especial na Rede Wyden Educacional. O procedimento metodológico baseia-se numa pesquisa quantiqualitativa, realizada com fontes documentais primárias extraídas do Banco de Dados do Censo da Educação Superior no período de 2009 a 2019 e dos websites das instituições da rede Wyden. Os resultados apontam que o financiamento estudantil é o principal financiador da rede Wyden, especialmente o financiamento público por meio do FIES e do ProUni. A predominância das matrículas de estudantes com financiamentos estudantis, sejam públicos ou privados, traz como implicação o aumento da privatização do ensino superior no País, em especial dos grupos empresariais ligados à financeirização do setor educacional, como a Wyden Educacional.

Palavras-chave: Financiamento Estudantil. Wyden Educacional. FIES. ProUni. Financeirização.

\section{Public Student Financing and the Expansion of Private Higher}

\section{Education in Brazil: the case of the Wyden Educational Network}

\begin{abstract}
This paper aims to analyze public student financing via FIES and ProUni and its impact on the expansion of private higher education in Brazil, especially in the Wyden Educacional Network. The methodological procedure is based on a quantitative and qualitative research, carried out with primary documentary sources extracted from the Higher Education Census Database from 2009 to 2019 and from the websites of the institutions of the Wyden network. The results show that student financing is the main sponsor of the Wyden network, especially public financing through FIES and ProUni. The predominance of student enrollments with student financing, whether public or private, implies an increase in the privatization of higher education in the country, especially of business groups linked to the financialization of the educational sector, such as Wyden Educacional.
\end{abstract}

Keywords: Student Financing. Wyden Education. FIES. ProUni. Financialization.

\footnotetext{
1 O texto apresenta resultados de projeto de pesquisa com financiamento do CNPq e da CAPES e foi aprovado no VIII Encontro Fineduca (2020), tendo sido atualizado para esta publicação.
} 
Financiamento Estudantil Público e a Expansão do Ensino Superior Privado no Brasil

\section{Introdução}

Este trabalho tem como objetivo analisar o financiamento estudantil com recursos do fundo público e seu impacto na expansão do ensino superior privado no Brasil. A predominância das matrículas de estudantes com financiamento estudantil público traz como implicação o aumento da privatização do ensino superior no País, cujo setor recebeu de financiamento via Fundo de Financiamento Estudantil (FIES) e Programa Universidade para Todos (ProUni), em 2019, mais de 1 milhão de matrículas, em especial os grupos empresariais ligados à financeirização do setor educacional, como a Wyden Educacional, a ser analisada neste estudo.

Nas últimas quatro décadas, vivencia-se, no Brasil, uma expansão acelerada do ensino superior privado, favorecido pelo governo federal por meio de um conjunto de leis, do qual destacam-se: a Constituição Federal de 1988, que autoriza, no artigo 209, a livre iniciativa do setor privado na oferta do ensino (BRASIL, 1988); a Lei de Diretrizes e Bases da Educação $n^{\circ}$ 9.394/1996, que regulamentou a oferta do ensino superior por instituições com fins lucrativos (BRASIL, 1996); e a Lei no 13.005/2014, que criou o Plano Nacional de Educação (PNE), no qual demarcou o espaço do setor privado no ensino superior, beneficiando-o através da ampliação de políticas como o FIES e o ProUni (BRASIL, 2014).

Outros fatores que podem explicar a expansão acelerada do setor privado no ensino superior estão relacionados à inserção do capital financeiro de grandes conglomerados educacionais em bolsas de valores, a partir de 2007, e à entrada de grandes redes estrangeiras no Brasil, em decorrência do processo de financeirização do ensino superior, a exemplo das redes Laureate International Universities e Wyden Educacional, cujas mantenedoras localizam-se nos Estados Unidos.

Dessa forma, este trabalho tem a finalidade de discutir como as políticas de financiamento estudantil público, por meio do FIES e do ProUni, têm contribuído para a expansão do ensino superior privado brasileiro, consequentemente, para a privatização desse nível de ensino, tendo como estudo de caso a Rede Wyden Educacional.

Durante a pesquisa, buscou-se responder às seguintes questões: quais são as implicações para o ensino superior brasileiro da predominância de matrículas com financiamento estudantil público em Instituições de Ensino Superior (IES) privadas? O que representa os recursos do financiamento estudantil público do FIES e do ProUni para a Rede Wyden Educacional? Qual é o impacto desse financiamento nas matrículas em cursos de graduação nas IES da Rede Wyden Educacional?

O procedimento metodológico baseia-se numa pesquisa quantiqualitativa, realizada com fontes documentais primárias, extraídas do Banco de Dados do Censo da Educação Superior, entre 2009 e 2019, e dos websites das instituições da rede Wyden. O período inicial do nosso recorte consiste no momento de inserção da Wyden no Brasil, e o período final corresponde à consolidação dos dados referentes ao ano de 2019, do último Censo da Educação Superior, publicados pelo Instituto Nacional de Estudos e Pesquisas Educacionais Anísio Teixeira (INEP).

O texto se estrutura em duas partes e mais as considerações finais. A primeira parte trata da expansão e do financiamento estudantil no ensino superior privado no Brasil. A segunda, apresenta uma análise das matrículas por tipo de financiamento estudantil na Rede 
Financiamento Estudantil Público e a Expansão do Ensino Superior Privado no Brasil

Wyden Educacional, entre 2009 e 2019, demonstrando que o financiamento estudantil público é um dos principais financiadores dessa rede.

\section{A expansão e o financiamento estudantil no ensino superior privado no Brasil}

A expansão do ensino superior é marcada por diferentes interesses e sucessivas lutas pelos recursos públicos, entre os setores público e privado. Desde 1930, já era possível verificar que o setor privado se beneficiava com vantagens concedidas pelo setor público, no âmbito do Estado, o que contribuiu para a expansão, a privatização e a consolidação de um mercado altamente lucrativo (SANTOS FILHO, 2016).

A materialização dessa expansão expressou-se por meio de uma vasta legislação que normatizou o ensino superior no Brasil. Destacando-se: a Constituição de 1934, que previa isenção de tributos para estabelecimentos particulares de ensino primário e profissional gratuitos (BRASIL, 1934); e a Constituição de 1946 (BRASIL, 1946), que isentou todas as instituições educacionais de qualquer tipo de tributos (federal, estadual e municipal), desde que fosse aplicada no Brasil toda a renda em fins educacionais (SANTOS FILHO, 2016).

Com a aprovação da Constituição em 1988, foi permitido o livre acesso à iniciativa privada na oferta do ensino, restringindo os recursos públicos somente para escolas com finalidades não lucrativas (públicas, comunitárias, confessionais ou filantrópicas) (BRASIL, 1988). Conforme Santos Filho (2016, p. 102), "A exigência de que, para receber recursos públicos, as instituições não podem ter propósitos de rentabilidade revela a possibilidade de existência de instituições com finalidades lucrativas".

Durante os governos de Fernando Henrique Cardoso (FHC) (1995-2002), foi sancionada a LDB 9.394/96 (BRASIL, 1996), que inaugurou legalmente um marco na política pública de expansão do ensino superior privado no País. Com sua aprovação, foi regulamentada a livre oferta do ensino superior por instituições privadas com fins lucrativos, permitindo que lucrem com a venda de serviços educacionais e recebam estímulos financeiros do Estado e da sociedade civil.

Essa expansão foi intensificada com a institucionalização do Decreto $n^{\circ}$ 2.306/1997 (BRASIL, 1997), que normatizou as atribuições das IES e a diversificação das tipologias em universidades, centros universitários, faculdades e escolas superiores. Destaca-se, ainda, a Lei $n^{\circ} 10.260 / 2001$, que instituiu o FIES e se constituiu numa importante política de financiamento do setor privado no Brasil (BRASIL, 2001).

Dando continuidade à política privatista, os governos de Luiz Inácio Lula da Silva (LULA) (2003-2010) incentivaram a expansão do ensino superior pela via privada, por meio de leis e decretos, dos quais destacam-se: o Decreto $n^{\circ}$ 4.914/2003 (BRASIL, 2003), que concedeu autonomia aos centros universitários; o Decreto $n^{\circ}$ 5.622/2005 (BRASIL, 2005a), que regulamentou a educação a distância no País; e a Lei n 11.096/2005, que criou o Programa Universidade para Todos (BRASIL, 2005b).

Segundo Chaves, esse conjunto de regulamentações "[...] fortalece e aprofunda a política de diversificação institucional e liberalização para a criação de instituições isoladas voltadas para o mercado, sendo decisivo para o crescimento explosivo do setor privado do ensino superior, no período pós-LDB" (CHAVES, 2010, p. 487). 
Financiamento Estudantil Público e a Expansão do Ensino Superior Privado no Brasil

Como resultado, observa-se a ampliação da privatização por meio da expansão de instituições (Gráfico 1) e matrículas do ensino superior privado no Brasil (Gráfico 2), como será mostrado a seguir.

Gráfico 1 - Evolução do número de Instituições de Ensino Superior por categoria administrativa - Brasil 1980-2019

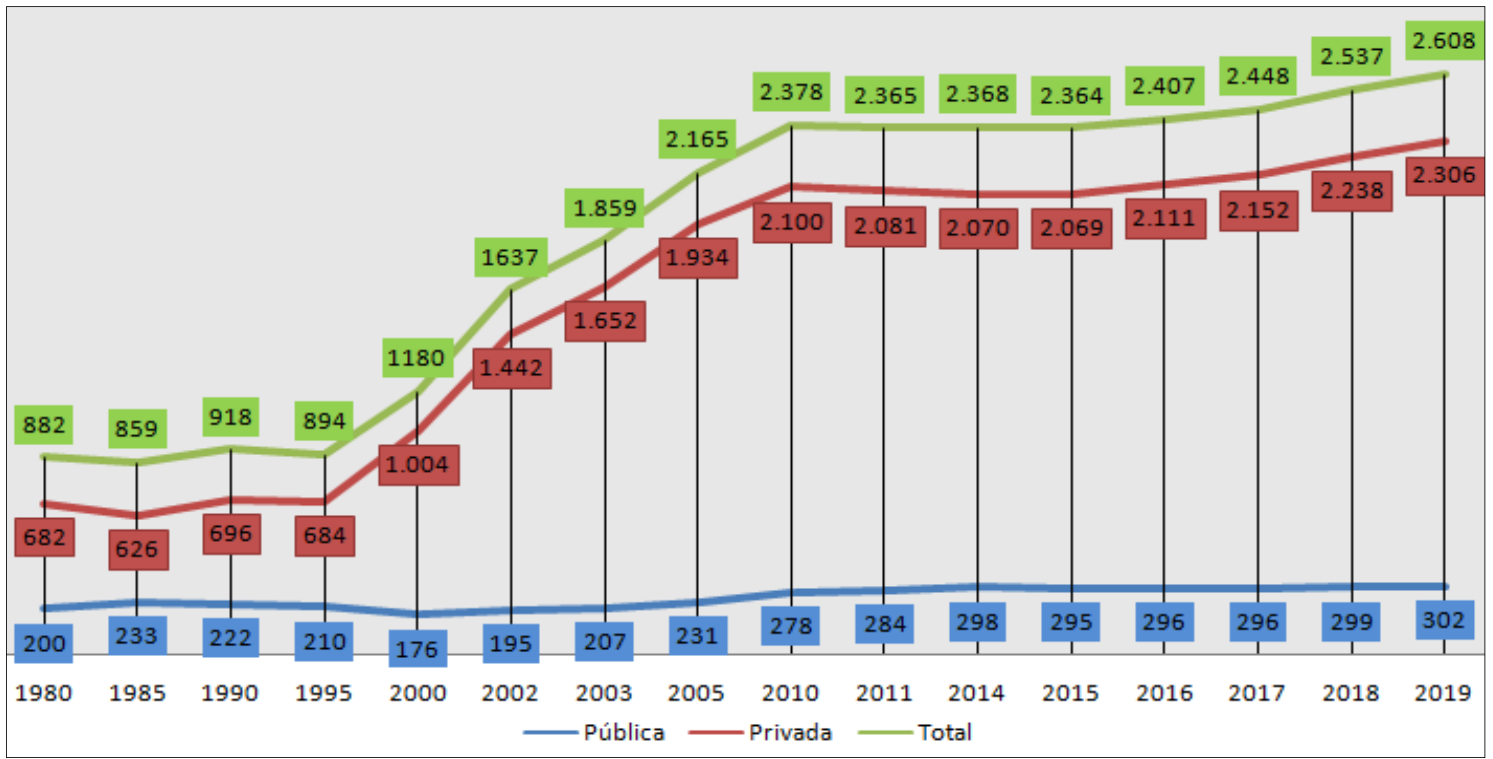

Fonte: Elaboração das autoras com base em registros do INEP (BRASIL, 2020a; 2020b).

Em 1980, o número de IES era de 882 e passou para 2.608 em 2019, um crescimento de 195,7\%. Comparando o setor público com o setor privado, observa-se que, em 1980, o número de IES privadas (682) representava $77,34 \%$ do total de IES, enquanto as públicas (200) detinham 22,67\% desse total. Os dados evidenciam que, de 1980 para 2019, houve um maior crescimento do setor privado em comparação com o público, pois, em 2019, o número de IES privadas passou para 2.306, um aumento de $238,1 \%$, e as IES públicas (302) cresceram $51,0 \%$. Comparando os dois setores, observa-se que, em 2019, as IES privadas representavam $88,34 \%$ de todas as IES, e, as públicas, apenas $11,57 \%$. Os dados também mostram que a expansão das IES do setor privado foi acentuada a partir de 1995 (início do governo de $\mathrm{FHC}$ ).

Conforme Chaves e Amaral (2016), entre 1995 e 2002, houve uma redução de 7,1\% (de 210 para 195) do número de instituições públicas e um aumento de 110,8\% (de 684 para 1.442) das instituições privadas, período que compreende os governos de FHC. Em 2002, havia 195 instituições públicas e 1.442 instituições privadas, passando para 207 e 1.652 em 2003, concomitantemente.

Entre 2003 e 2010, nos governos de Lula, tanto o setor público como o setor privado expandiram o número de IES. Em 2003, o setor público tinha 207 IES e, o privado, 1.652. Em 2010, o público passou a ter 278 , um aumento de $34,3 \%$, e, o privado, 2.100 , um acréscimo de $27,1 \%$. No primeiro governo de Dilma Rousseff (2011-2014), houve um crescimento de $7,2 \%$ no número de IES públicas, passando de 278 para 298. Quanto ao setor privado, reduziu-se o número de IES, passando de 2.100 para $2.070(-1,4 \%)$. Para os autores, o crescimento das IES públicas nos dois governos (Lula e Dilma) deve-se à "[...] criação de novas universidades federais e [à] transformação dos Centros Federais de Educação 
Financiamento Estudantil Público e a Expansão do Ensino Superior Privado no Brasil

Tecnológica (CEFETs) em Institutos Federais de Educação, Ciência e Tecnologia" (CHAVES; AMARAL, 2016, p. 56).

Como bem elucidam Chaves e Amaral, a redução no número de IES privadas de 2010 para 2015 deve-se ao "[...] movimento de fusões das IES desse setor, como consequência do processo de financeirização que o atingiu, a partir do ano de 2007, com a criação de redes de empresas" (CHAVES; AMARAL, 2016, p. 58), que passaram a ofertar ações na bolsa de valores, e com a entrada de grupos estrangeiros no ensino superior, que adquiriram várias instituições de pequeno porte no País.

Chaves, Santos e Kato (2020) afirmam que o processo de financeirização na educação superior privada segue a lógica do mercado financeiro, cujos negócios se baseiam na especulação. Assim,

A presença do capital especulativo e do capital estrangeiro também se evidencia com o ingresso de grandes grupos educacionais internacionais que passam a atuar diretamente no sistema educacional brasileiro por meio da compra de instituições nacionais. São os casos da Laureate Education (conglomerado americano de universidades, com inserção em diversos países, que têm entre seus sócios o fundo de private equity da KKR, o Banco Mundial e a Universidade Harvard) e a Wyden, exDevry, Internacional (empresa americana de capital aberto pertencente ao grupo Adtalem Global Education com inserção em diversos países) (CHAVES; SANTOS; KATO, 2020, p. 9).

A assertiva das autoras demonstra que o capitalismo, em sua fase atual - sob a lógica financeirizada e especulativa -, tem contribuído para que a movimentação do capital financeiro se faça também por meio da atuação de empresas estrangeiras no ensino superior brasileiro, como é o caso da Wyden Educacional.

Cabe ressaltar que esse movimento de fusões, de criação de redes, de oferta de ações nas bolsas de valores e de entrada de grupos estrangeiros como a Wyden e a Laureate no País acirrou a concorrência e consolidou a formação de grandes oligopólios (CHAVES, 2010), como, por exemplo: a Cogna (ex-Kroton) e a YDUQS (ex-Estácio Participações S.A), os dois maiores grupos educacionais brasileiros.

Chaves e Amaral ressaltam que, apesar de o número de IES privadas não ter aumentado de 2010 a 2015, houve um forte crescimento no número de matrículas nesse setor, "potencializado pelo financiamento às famílias, propiciado pelo ProUni e pelo FIES" (CHAVES; AMARAL, 2016, p. 56).

Em 1980, havia 1,38 milhões de estudantes matriculados em cursos no ensino superior no Brasil, sendo 890 mil no setor privado e 490 mil no público. Em 2019, das 8,6 milhões de matrículas, 6,52 milhões estavam no setor privado e 2,08 milhões no setor público. Significa que o setor privado detinha, nesse ano, $88 \%$ das instituições e $75 \%$ das matrículas do ensino superior brasileiro, conforme o gráfico a seguir. 
Financiamento Estudantil Público e a Expansão do Ensino Superior Privado no Brasil

Gráfico 2 - Evolução do número de matrículas no Ensino Superior, por categoria administrativa - Brasil 1980-2019, em milhões

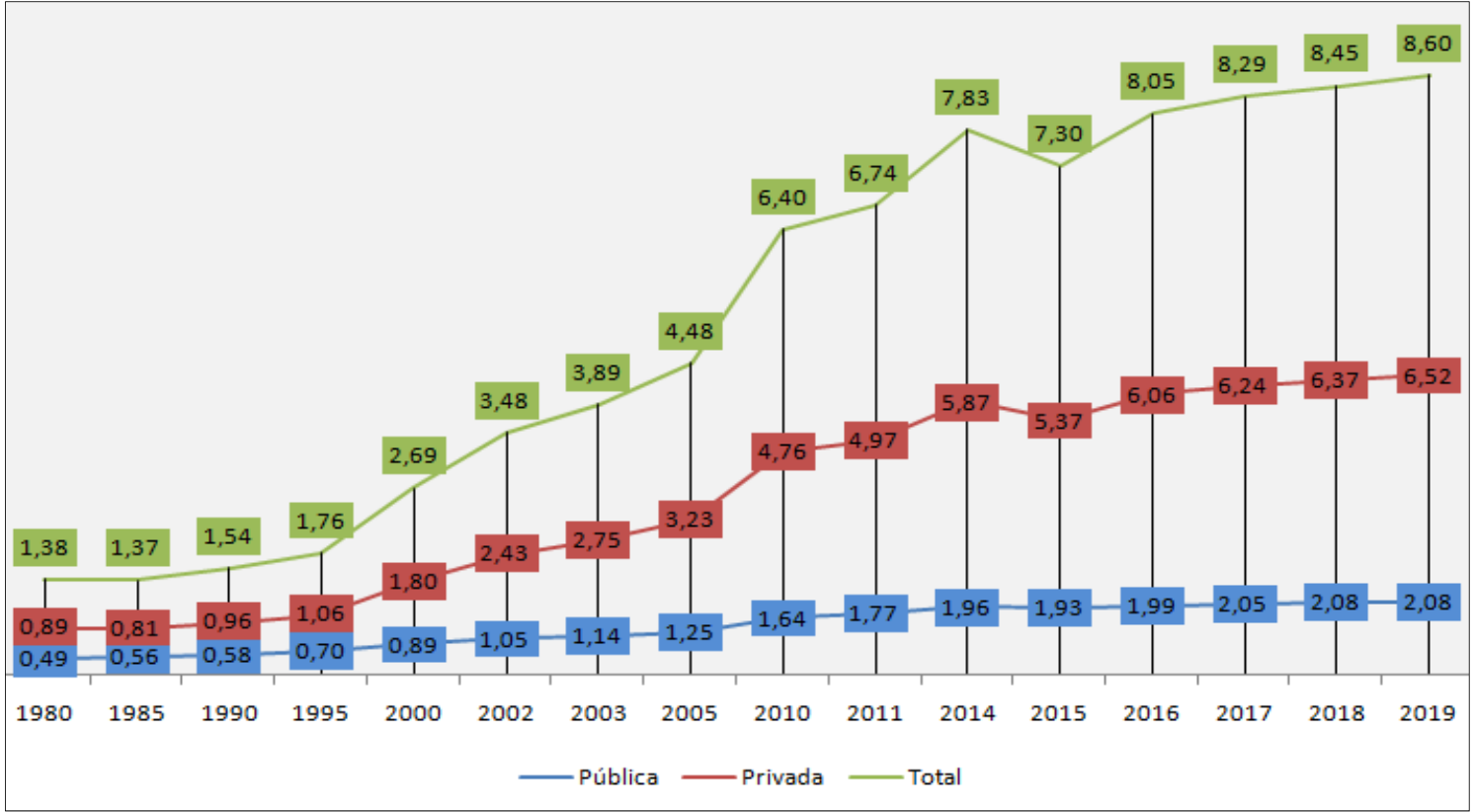

Fonte: Elaboração das autoras com base em registros do INEP (BRASIL, 2020a; 2020b).

Vê-se a evolução crescente das matrículas no ensino superior brasileiro no período analisado, mas também uma redução delas em -6,8\% (nos dois setores, público e privado), passando de 7,83 milhões, em 2014, para 7,3 milhões em 2015. No setor privado, a redução foi de $-8,5 \%$ de estudantes matriculados, maior que no setor público, cuja redução foi de $1,5 \%$.

Conforme Santos Filho (2016), o acesso da classe trabalhadora ao ensino superior por meio de políticas como o FIES e o ProUni, prioritariamente pela educação a distância, em vez de possibilitar a democratização desse nível de ensino, tem penalizado as famílias com a cobrança dos empréstimos pelos bancos, implicando o endividamento dos estudantes e de seus familiares.

As afirmações de Chaves e Amaral (2016) e Santos Filho (2016) podem ser comprovadas no Gráfico 2, em que se observa o crescimento das matrículas entre 2005 e 2010, período correspondente à criação do ProUni e à expansão do FIES. O ProUni foi criado pela Lei $n^{\circ} 11.096 / 2005$, destinado à concessão de bolsas de estudos integrais e parciais de $50 \%$ ou de $25 \%$ para estudantes que desejam realizar cursos de graduação e sequenciais de formação específica, em IES privadas, com ou sem fins lucrativos (BRASIL, 2005b).

Mancebo (2004) chama atenção para o aspecto privatizante do ProUni, pois o Estado, ao delegar suas responsabilidades públicas da oferta do ensino superior para IES privadas, mesmo através de bolsas sem custos aos estudantes, contribui para a expansão da oferta desse nível de ensino de forma privada.

Em contrapartida a essa oferta, as IES privadas, com ou sem fins lucrativos, ao aderirem ao ProUni, recebem isenções fiscais nos tributos de Imposto de Renda Pessoa Jurídica (IRPJ), de Contribuição Social sobre Lucro Líquido (CSLL), de Contribuição para o 
Financiamento Estudantil Público e a Expansão do Ensino Superior Privado no Brasil

Financiamento da Seguridade Social (COFINS) e do Programa de Integração Social (PISPASEP) (BRASIL, 2005b).

Essa lógica de isenções tributárias, instaurada desde a Constituição de 1946 e mantida na Constituição de 1988, além de ser bem lucrativa (redução dos tributos), favorece o preenchimento de vagas ociosas nas IES privadas, "tudo sob o discurso da ampliação do acesso ao ensino superior pelos mais pobres" (SANTOS FILHO, 2016, p. 150).

Conforme Guimarães, as receitas das renúncias fiscais do IRPJ vinculadas ao ProUni geram "[...] uma queda nos repasses desses fundos para manutenção e desenvolvimento do ensino público federal, estadual e municipal" (GUIMARÃES, 2018, p. 250). Apesar de as isenções dos demais tributos não estarem vinculadas à educação, os recursos deixam de ser destinados às suas áreas específicas para serem transferidos ao setor privado por meio do pagamento de bolsas (CHAVES; AMARAL, 2016).

O FIES foi criado em 1999 pela Medida Provisória n 1.865-4 (BRASIL, 1999) e regulamentado pela Lei 10.260/2001 (BRASIL, 2001), substituindo o Programa de Crédito Educativo para Crianças Carentes (CREDUC), criado pela Lei ${ }^{\circ} 8.436 / 1992$ (BRASIL, 1992). Sua finalidade: conceder financiamento estudantil aos alunos regularmente matriculados em cursos de graduação ${ }^{2}$ não gratuitos.

A Lei $n^{\circ} 10.260 / 2001$, em seu artigo $7^{\circ}$, também autoriza a União a emitir título da dívida pública em favor do FIES, devendo ser usado, exclusivamente, para "[...] pagamento às mantenedoras de instituições de ensino dos encargos educacionais relativos às operações de financiamento realizadas com recursos desse Fundo" (BRASIL, 2001). Pode, ainda, ser utilizado para o pagamento de contribuições sociais (artigo $10^{\circ}$ ) e, na ausência de encargos previdenciários, "para o pagamento de quaisquer tributos administrados pela Secretaria da Receita Federal do Brasil” (BRASIL, 2001).

Na Tabela 1, a seguir, apresenta-se a evolução dos recursos destinados ao FIES e dos gastos tributários com o ProUni, entre 2003 e 2019. Observa-se que, nesse período, houve uma renúncia fiscal das IES privadas que aderiram ao programa, em torno de 21 bilhões. $\mathrm{E}$ também que as renúncias tributárias vinculadas ao ProUni apresentam um movimento ascendente anualmente, totalizando um crescimento de 1.028,6\%, entre 2005 (primeiro ano da execução do ProUni) e 2019.

2 A partir de 2010, além dos cursos de graduação, o FIES passou a financiar cursos de pós-graduação (mestrado e doutorado) e de educação profissional técnica de nível médio, incluídos por meio da Lei n 12.202 , de 14 de janeiro de 2010 (BRASIL, 2010). 
Financiamento Estudantil Público e a Expansão do Ensino Superior Privado no Brasil

Tabela 1 - Recursos destinados ao FIES e gastos tributários com o ProUni no período de 2003 a 2019 - Valores (R\$) a preços de janeiro de 2020 (IPCA)

\begin{tabular}{c|c|c|c}
\hline ANO & FIES & PROUNI & FIES + PROUNI \\
\hline 2003 & 1.740 .246 .800 & 0 & 1.740 .246 .800 \\
\hline 2004 & 1.605 .355 .082 & 0 & 1.605 .355 .082 \\
\hline 2005 & 1.693 .955 .066 & 229.703 .344 & 1.923 .658 .410 \\
\hline 2006 & 1.887 .510 .129 & 445.947 .177 & 2.333 .457 .306 \\
\hline 2007 & 1.933 .405 .826 & 695.104 .840 & 2.628 .510 .665 \\
\hline 2008 & 2.204 .787 .387 & 818.829 .805 & 3.023 .617 .191 \\
\hline 2009 & 2.493 .956 .160 & 954.048 .980 & 3.448 .005 .140 \\
\hline 2010 & 2.952 .616 .367 & 989.624 .577 & 3.942 .240 .944 \\
\hline 2011 & 3.959 .461 .504 & 906.248 .220 & 4.865 .709 .723 \\
\hline 2012 & 8.159 .295 .188 & 1.155 .063 .437 & 9.314 .358 .625 \\
\hline 2013 & 10.860 .086 .111 & 1.516 .281 .507 & 12.376 .367 .618 \\
\hline 2014 & 16.524 .357 .202 & 1.523 .921 .359 & 18.048 .278 .561 \\
\hline 2015 & 18.195 .694 .384 & 2.140 .297 .404 & 20.335 .991 .788 \\
\hline 2016 & 20.348 .127 .048 & 2.469 .469 .600 & 22.817 .596 .648 \\
\hline 2017 & 22.134 .150 .567 & 2.511 .284 .972 & 24.645 .435 .539 \\
\hline 2018 & 13.160 .113 .448 & 2.539 .340 .483 & 15.699 .453 .931 \\
\hline 2019 & 10.126 .273 .844 & 2.592 .515 .002 & 12.718 .788 .846 \\
\hline Total & $\mathbf{1 3 9 . 9 7 9 . 3 9 2 . 1 1 3}$ & $\mathbf{2 1 . 4 8 7 . 6 8 0 . 7 0 7}$ & $\mathbf{1 6 1 . 4 6 7 . 0 7 2 . 8 1 7}$ \\
\hline $\mathbf{2 0 0 3 - 2 0 1 9 ( \% )}$ & $\mathbf{4 8 1 , 9}$ & $\mathbf{1 0 2 8 , 6}$ & $\mathbf{6 3 0 , 8 6 \%}$ \\
\hline
\end{tabular}

Fonte: Câmara dos Deputados (2021) e Brasil, 2006-2020.

A tabela também mostra que o FIES teve um custo de R\$139 bilhões entre 2003 e 2019. Em 2017, o FIES destinou o maior volume de recursos para as IES privadas (22 bilhões). E, a partir de 2018, vem ocorrendo uma redução em cerca de $50 \%$ nos recursos destinados ao FIES, devido à mudança nos critérios para a concessão dos empréstimos ocorrida a partir de 2015, uma vez que foi detectada grande inadimplência no pagamento dos empréstimos feitos pelos estudantes e que o Programa não se sustentava (SANTOS FILHO, 2016). Juntos, o FIES e o ProUni tiveram um custo de R\$ 161 bilhões. Quanto ao FIES, por ser um programa de concessão de empréstimos aos estudantes, apesar da inadimplência citada anteriormente, há um retorno de parte desses recursos aos cofres públicos.

Contraditoriamente, o Estado, com o discurso da crise fiscal, exige maior arrecadação tributária e realiza cortes nos gastos e nos investimentos da União, a exemplo da Emenda Constitucional 95/2016 (BRASIL, 2016), que instituiu um novo regime fiscal. Contudo, ao conceder recursos por meio de isenções fiscais e previdenciárias para IES privadas, reduz 0 arrecadamento e aumenta o endividamento do Estado (SANTOS FILHO, 2016).

Guimarães (2018) ressalta que a inadimplência no pagamento do FIES por parte dos estudantes pode ser explicada pelas mudanças nas regras do financiamento em 2005, quando este passou a não exigir fiador e aumentou a exigência de maior renda dos estudantes, configurando fatores contraditórios que contribuíram para o nível de inadimplência. 
Financiamento Estudantil Público e a Expansão do Ensino Superior Privado no Brasil

Segundo o autor, a tendência de inadimplência do FIES também é alta devido à flexibilidade nos critérios de aprovação do crédito, como juros reduzidos, prazos mais longos e a não exigência de garantia patrimonial. Sobretudo quando a "[...] operacionalização do FIES ocorre com o Tesouro Nacional se responsabilizando mensalmente pelas despesas educacionais dos alunos com as IES privadas até o término do curso, período de utilização" (GUIMARÃES, 2018, p. 261).

Após esse período de utilização, todo egresso terá 18 meses para iniciar o pagamento (período de carência), sendo obrigado a pagar trimestralmente os mesmos juros do período anterior. Finalizada a carência, o egresso deve começar a pagar o saldo devedor do financiamento (período de amortização), podendo parcelar por um período de até 3 vezes o tempo de permanência no curso financiado pelo FIES (BRASIL, 2021).

A única certeza que os egressos beneficiados pelo FIES possuem ao término dos cursos é o da dívida contraída. Sendo mais problemáticos os casos dos egressos que realizaram cursos em IES com qualidade duvidosa, pois, além da dívida, são responsáveis por sua (con)formação, seu (des)emprego e/ou seu (in)sucesso profissional.

Nesse contexto, é importante analisar o impacto do financiamento estudantil nas matrículas em IES privadas. Os tipos de matrículas por financiamentos estudantis se dividem em reembolsáveis e não reembolsáveis, e são administrados pelos governos federal, estadual e municipal, pela própria IES, por entidades externas à IES e por outras entidades, segundo o INEP (BRASIL, 2020b).

O Gráfico 3 apresenta os quatro maiores tipos de financiamentos estudantis no setor privado do Brasil, entre 2009 e 2019. São eles: o FIES e o ProUni (financiamentos públicos), o Crédito por Entidades Externas e o Crédito Próprio IES (financiamentos privados).

Gráfico 3 - Evolução do número de matrículas no ensino superior privado, com financiamento estudantil público e privado - Brasil 2009-2018, em milhões

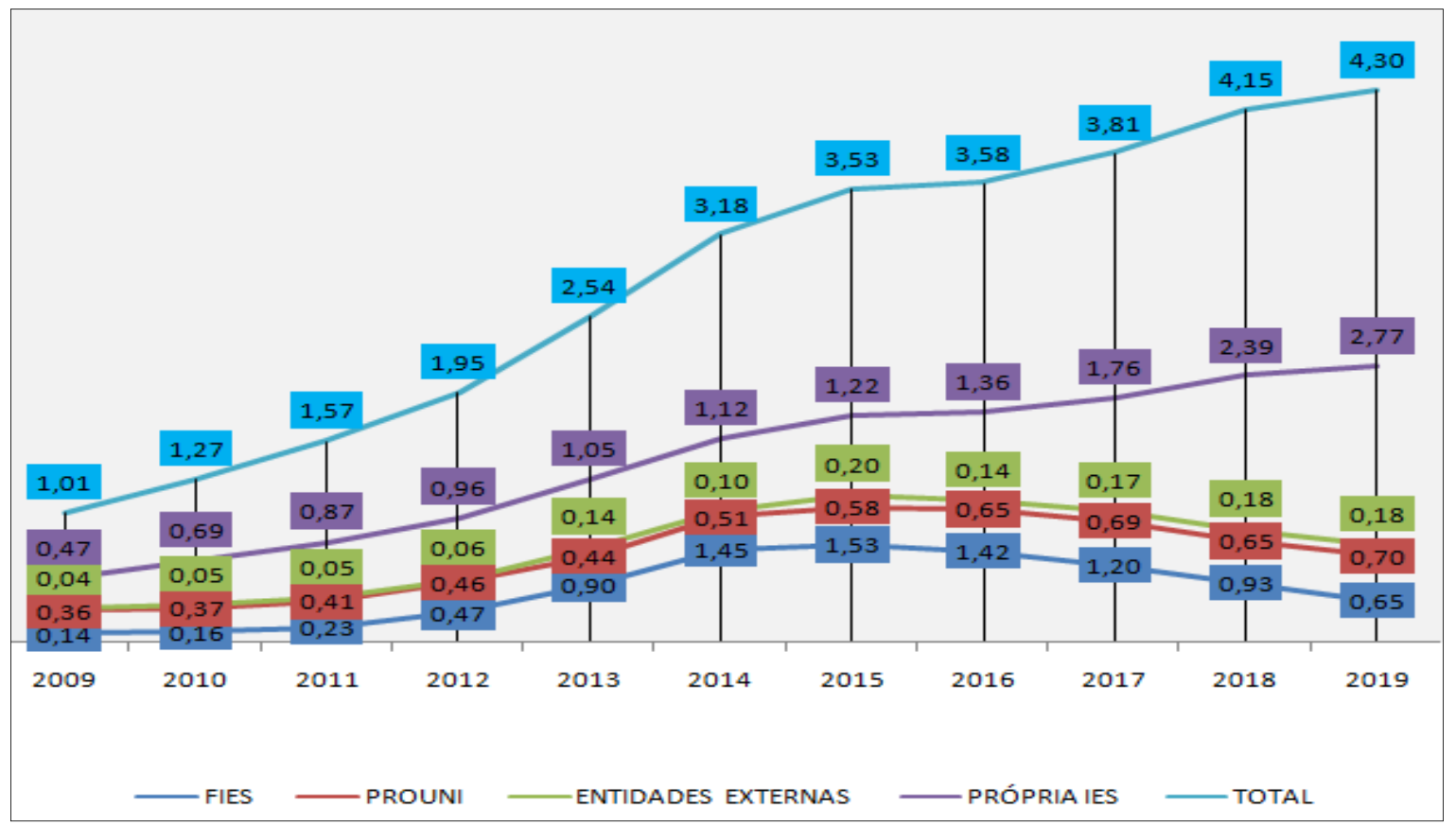

Fonte: Elaboração das autoras com base em registro do INEP (BRASIL, 2020b). 
Financiamento Estudantil Público e a Expansão do Ensino Superior Privado no Brasil

Observa-se que o total de matrículas no setor privado com financiamento estudantil (público e privado) é muito elevado, com 4,3 milhões de estudantes financiados, representando 66\% dos matriculados nesse setor em 2019 (6,52 milhões - vide Gráfico 2). Contudo, cabe ressaltar que um mesmo estudante pode obter mais de um financiamento estudantil, pois os microdados do Censo da Educação Superior, quando analisados no Programa Statistical Package for the Social Sciences (SPSS), somam os diferentes tipos de financiamento que ele pode ter. Como exemplos: dois públicos (FIES e ProUni), dois privados (Própria IES e Entidades Externas) e a junção dos públicos e privados.

É importante destacar que, de 2010 a 2015, houve uma explosão do financiamento público por meio do FIES, resultado das mudanças implementadas em 2010, nas regras de concessão do FIES. Em 2010, o FIES financiou aproximadamente 160 mil matrículas no setor privado. Em 2015, foi financiado um total de 1 milhão e 530 mil estudantes, um crescimento de $990 \%$ no total das matrículas do setor privado.

Guimarães mostra que esse crescimento se acelerou a partir do tripé "[...] a não exigência de fiador, a redução dos juros e a facilitação dos critérios de seleção" (GUIMARÃES, 2018 , p. 265), ocorridas com as mudanças no programa em 2010. E mais as possibilidades de abatimento do saldo devedor por professores e médicos, implicando o fortalecimento do setor privado, devido à ampliação e à facilitação do acesso ao ensino superior por meio do FIES.

No entanto, a partir de 2016, o FIES registrou decréscimos no número de contratos, finalizando o ano de 2019 com 650 mil estudantes financiados, uma redução de $135 \%$ em comparação a 2015. Já o ProUni apresentou crescimento, saindo de 360 mil estudantes matriculados, em 2009, para 700 mil em 2019, um aumento de $94 \%$ no total de matrículas com as bolsas do ProUni. Apesar da redução do número de matrículas por meio do FIES, o volume de recursos públicos transferidos para o setor privado permaneceu elevado.

A redução deve-se à crise e às mudanças nas regras de concessão do FIES pelo governo federal a partir de 2015. Para atenuá-la, as IES privadas estão investindo no financiamento próprio, como se pode observar no crescimento de matrículas via Crédito Próprio IES. Esse tipo de financiamento passou de 490 mil estudantes, em 2009, para 2 milhões, 770 mil estudantes em 2019, um aumento de $465 \%$ no total das matrículas com financiamento próprio das IES. Ressalta-se que o Crédito Próprio das IES teve um pequeno declínio apenas em 2013 e 2014, por conta do crescimento daquele período no FIES.

Conforme Sousa, a política de financiamento estudantil iniciada com o FIES e o ProUni induziu a "oferta e a expansão de linhas variadas de financiamento estudantil privado" (SOUSA, 2019, p. 17). A autora dá como exemplo a Estácio Participações, que criou uma linha de financiamento estudantil própria, o Parcelamento Estácio (PAR), ou mesmo o Parcelamento Estudantil Privado (PEP), linha de financiamento próprio da Kroton.

Em pesquisa sobre o PEP da Kroton, Reis (2019, p. 149) aponta que:

O PEP tem sido para a Kroton Educacional uma forma de reaver algo do que se havia perdido, com a diminuição dos contratos do Fies, e uma ampla oportunidade de expandir o seu alunado, colocando à sua disposição inúmeros serviços de financiamento estudantil na busca de capturar seus clientes em seus diversos perfis.

A autora ressalta que, entre as ações da Kroton para atrair clientes, mantendo os alunos matriculados, está a diversificação dos serviços de crédito estudantil, por meio da "[...] oferta 
Financiamento Estudantil Público e a Expansão do Ensino Superior Privado no Brasil

de seu parcelamento, usufruto do capital próprio da Kroton; do capital de instituições financeiras, como é o caso do PraValer, que está presente na instituição; e do fundo público por meio do Fies" (REIS, 2019, p. 149).

O Pravaler e os demais financiamentos das entidades externas às IES representaram 0,18 milhões do total de matrículas das IES privadas em 2019. Naquele ano, essas entidades realizaram 2,95 milhões de matrículas: $34,3 \%$ do total de matrículas do ensino superior. Nesse sentido, o setor privado lucra com o financiamento próprio e com os benefícios do Estado por meio do FIES e do ProUni, tornando o ensino superior brasileiro predominantemente privado.

\section{O financiamento estudantil na Rede Wyden Educacional}

A Wyden Educacional entrou no Brasil em 2009, a partir da aquisição de uma rede bem consolidada de faculdades na região Nordeste, sob o nome DeVry Brasil. Buscando alcançar o seu objetivo de se tornar "a principal rede de ensino superior das Regiões Norte e Nordeste do Brasil" (WYDEN EDUCACIONAL, 2010, p. 5), comprou um total de 12 instituições de ensino superior, sendo nove na região Nordeste, duas na região Norte e uma na região Sudeste, a fim de ampliar seu nicho de mercado no Brasil.

A rede oferece um leque de oportunidades para atrair sua clientela, que vão dos "benefícios internacionais", como cursos de inglês subsidiados; intercâmbios e jornadas para EUA, China e alguns países da Europa; premiações com viagens para os melhores alunos; experiências e infraestruturas internacionais (WYDEN EDUCACIONAL, 2021a), aos "benefícios nacionais": concessão de bolsas como o ProUni e financiamentos estudantis como o FIES e o Pravaler Crédito Universitário.

O Pravaler ${ }^{3}$ é o maior programa de crédito estudantil privado do Brasil, criado em 2001 pela Ideal Invest S.A., tem como objetivo ofertar financiamento estudantil em parceria com as IES privadas. Atualmente, possui parceria com mais de 500 IES, atende quase 200 mil alunos e financia mais de 2 bilhões em mensalidades no setor privado (PRAVALER, 2021).

A rede Wyden, em parceria com o Pravaler, oferece financiamentos de até $100 \%$ das mensalidades. Ao firmar o contrato, o estudante se responsabiliza por pagar metade da mensalidade enquanto realiza o curso, e o saldo devedor somente depois de formado, com o discurso do não pagamento de juros (WYDEN EDUCACIONAL, 2021b).

Com todas as vantagens que, aparentemente, a rede Wyden pode oferecer para os seus futuros clientes, especialmente as relacionadas às bolsas e aos financiamentos estudantis, é de se esperar que haja uma incidência relevante de matrículas por essas modalidades. Tal afirmação pode ser confirmada na Tabela 2, em que o financiamento estudantil corresponde a uma média superior a $50 \%$ do total das matrículas da rede Wyden, entre 2009 e 2019.

3 Seus principais investidores são: "Fundo gerido pela EOS Investimentos, gestora de recursos de terceiros; BPrint LLC; Banco Itaú; Ribbit Capital; Executivos e ex-gestores de diversos setores” (PRAVALER, 2021). 
Financiamento Estudantil Público e a Expansão do Ensino Superior Privado no Brasil

Tabela 2 - Matrículas da Wyden por tipo de financiamento - 2009 a 2019

\begin{tabular}{cccccc}
\hline ANO & \multicolumn{2}{c}{ SEM FINANCIAMENTO } & \multicolumn{2}{c}{ COM FINANCIAMENTO } & TOTAL \\
\hline $\mathbf{2 0 0 9}$ & 3.324 & $44,32 \%$ & 4.176 & $55,68 \%$ & $\mathbf{7 . 5 0 0}$ \\
$\mathbf{2 0 1 0}$ & 6.903 & $58,69 \%$ & 4.859 & $41,31 \%$ & $\mathbf{1 1 . 7 6 2}$ \\
$\mathbf{2 0 1 1}$ & 7.538 & $58,60 \%$ & 5.325 & $41,40 \%$ & $\mathbf{1 2 . 8 6 3}$ \\
$\mathbf{2 0 1 2}$ & 12.389 & $53,36 \%$ & 10.827 & $46,64 \%$ & $\mathbf{2 3 . 2 1 6}$ \\
$\mathbf{2 0 1 3}$ & 17.972 & $52,65 \%$ & 16.162 & $47,35 \%$ & $\mathbf{3 4 . 1 3 4}$ \\
$\mathbf{2 0 1 4}$ & 17.305 & $42,13 \%$ & 23.773 & $57,87 \%$ & $\mathbf{4 1 . 0 7 8}$ \\
$\mathbf{2 0 1 5}$ & 26.663 & $49,26 \%$ & 27.463 & $50,74 \%$ & $\mathbf{5 4 . 1 2 6}$ \\
$\mathbf{2 0 1 6}$ & 14.267 & $29,92 \%$ & 33.424 & $70,08 \%$ & $\mathbf{4 7 . 6 9 1}$ \\
$\mathbf{2 0 1 7}$ & 23.340 & $49,10 \%$ & 24.192 & $50,90 \%$ & $\mathbf{4 7 . 5 3 2}$ \\
$\mathbf{2 0 1 8}$ & 19.197 & $40,23 \%$ & 28.520 & $59,77 \%$ & $\mathbf{4 7 . 7 1 7}$ \\
$\mathbf{2 0 1 9}$ & 21.439 & $37,38 \%$ & 35.910 & $62,62 \%$ & $\mathbf{5 7 . 3 4 9}$ \\
\hline
\end{tabular}

Fonte: Elaboração das autoras com base em registro do INEP (BRASIL, 2020b).

Destaque para o ano de 2016 , em que o percentual chegou a $70 \%$, encerrando o ano de 2019 com 62,62\% do total das matrículas via financiamento estudantil. Essa predominância de matrículas via financiamento garante uma parte significativa das receitas da rede Wyden, transformando essa modalidade de financiamento "num investimento atrativo com retorno garantido e risco reduzido pelo suporte do governo" (GUIMARÃES, 2018, p. 143).

Contraditoriamente, o financiamento estudantil, ao mesmo tempo que possibilita o acesso da classe trabalhadora ao ensino superior, transforma o direito do acesso de forma gratuita e ampla nas universidades públicas numa dívida compulsória. Além de contribuir para a maximização dos lucros das IES privadas, os estudantes convivem com os riscos da não empregabilidade e da insegurança da não geração de renda após a conclusão dos cursos (GUIMARÃES, 2018).

No financiamento estudantil público, destacam-se o FIES, no grupo dos reembolsáveis, e o ProUni (integral e parcial), no grupo dos não reembolsáveis, já no financiamento privado, sobressai o crédito financiado pela própria IES (ver Tabela 3). 
Financiamento Estudantil Público e a Expansão do Ensino Superior Privado no Brasil

Tabela 3 - Matrículas por Tipo de Financiamento Estudantil Wyden - 2009 a 2018

\begin{tabular}{|c|c|c|c|c|c|c|c|c|c|c|c|}
\hline \multicolumn{12}{|c|}{ FINANCIAMENTO ESTUDANTIL REEMBOLSÁVEL } \\
\hline TIPO DE FINANCIAMENTO & 2009 & 2010 & 2011 & 2012 & 2013 & 2014 & 2015 & 2016 & 2017 & 2018 & TOTAL \\
\hline FIES & 819 & 1.048 & 2.508 & 6.341 & 9.526 & 14.555 & 18.623 & 20.501 & 15.145 & 12.943 & 102.009 \\
\hline GOVERNO ESTADUAL & 0 & 0 & 0 & 0 & 0 & 0 & 0 & 0 & 0 & 0 & $\mathbf{0}$ \\
\hline GOVERNO MUNICIPAL & 0 & 0 & 0 & 0 & 0 & 0 & 0 & 0 & 0 & 0 & 0 \\
\hline ADMINISTRADO PELA IES & 0 & 0 & 0 & 120 & 36 & 23 & 3 & 1 & 1 & 1 & 185 \\
\hline $\begin{array}{l}\text { ADMINISTRADO POR } \\
\text { ENTIDADES EXTERNAS À IES }\end{array}$ & 0 & 0 & 0 & 84 & 47 & 6 & 152 & 947 & 725 & 2.521 & 4.482 \\
\hline $\begin{array}{l}\text { ADMINISTRADO POR } \\
\text { OUTRAS ENTIDADES }\end{array}$ & 4 & 0 & 0 & 129 & 0 & 0 & 0 & 0 & 0 & 0 & 133 \\
\hline \multicolumn{12}{|c|}{ FINANCIAMENTO ESTUDANTIL NÃO REEMBOLSÁVEL } \\
\hline TIPO DE FINANCIAMENTO & 2009 & 2010 & 2011 & 2012 & 2013 & 2014 & 2015 & 2016 & 2017 & 2018 & TOTAL \\
\hline PROUNI INTEGRAL & 655 & 1.039 & 1.002 & 1.710 & 1.785 & 2.075 & 2.691 & 2.927 & 2.198 & 2.328 & 18.410 \\
\hline PROUNI PARCIAL & 158 & 724 & 1.274 & 1.834 & 2.547 & 3.529 & 4.787 & 11.177 & 8.426 & 11.275 & 45.731 \\
\hline GOVERNO ESTADUAL & 57 & 36 & 11 & 0 & 0 & 7 & 0 & 0 & 0 & 0 & 111 \\
\hline GOVERNO MUNICIPAL & 78 & 115 & 0 & 0 & 0 & 443 & 155 & 264 & 206 & 325 & 1.586 \\
\hline ADMINISTRADO PELA IES & 2.172 & 1.872 & 1.226 & 1.751 & 2.269 & 2.827 & 4.641 & 5.391 & 3.522 & 999 & 26.670 \\
\hline $\begin{array}{l}\text { ADMINISTRADO POR } \\
\text { ENTIDADES EXTERNAS À IES }\end{array}$ & 0 & 0 & 0 & 0 & 0 & 960 & 153 & 0 & 0 & 0 & 1.113 \\
\hline $\begin{array}{l}\text { ADMINISTRADO POR } \\
\text { OUTRAS ENTIDADES }\end{array}$ & 0 & 335 & 0 & 126 & 0 & 0 & 0 & 0 & 0 & 0 & 461 \\
\hline
\end{tabular}

Fonte: Elaboração das autoras com base em registro do INEP (BRASIL, 2020b).

Representando o grupo dos financiamentos reembolsáveis, temos o FIES. Em 2009, a rede Wyden matriculou 819 estudantes e, em 2019, foram 18.236 estudantes por meio do FIES, um crescimento de $2.126 \%$. De 2014 a 2019, o percentual de matrículas via FIES manteve-se acima dos 50\%. E foi ainda maior em 2016, registrando $61,33 \%$ dos financiamentos e $42,98 \%$ das matrículas.

Em 2018, houve uma queda no percentual de matrículas do FIES, representando $45,38 \%$ dos financiamentos e $27,12 \%$ do total das matrículas. Em 2019, o número de financiamentos do FIES chegou a 40,9\% em relação ao ano anterior, representando $50,78 \%$ do total dos financiamentos estudantis e $31,8 \%$ do total de matrículas da rede Wyden.

O grupo dos financiamentos não reembolsáveis divide-se em dois: o financiamento público, cujo maior representante é o ProUni (integral e parcial), e o privado, realizado pela própria instituição ou por entidades externas.

No ano de 2009, o percentual de financiamentos por meio do ProUni foi de $19,46 \%$ e $10,84 \%$ do total das matrículas. Em 2016, o percentual aumentou, passando para $42,20 \%$ do total de financiamentos e $29,60 \%$ do total de matrículas. Em 2019, o percentual de matrículas cresceu $55,74 \%$ em comparação a 2018 , representando $59 \%$ do total dos financiamentos e $36,94 \%$ do total das matrículas.

Em contrapartida, o percentual do financiamento estudantil privado cresceu. Em 2009, seu total correspondeu a 52,10\% e, o total de matrículas, a 29,01\%. Destacando-se o ano de 2019 , com um crescimento de $662,6 \%$ se comparado a 2018 , representando $74,77 \%$ do total dos financiamentos privados e $46,82 \%$ do total das matrículas.

Contudo, cabe ressaltar uma dificuldade na análise dos dados sobre as matrículas realizadas através dos financiamentos estudantis, devido à possibilidade de um mesmo estudante possuir mais de um tipo de financiamento, como já foi comentado anteriormente. 
Financiamento Estudantil Público e a Expansão do Ensino Superior Privado no Brasil

Somando os valores de todos os financiamentos do período de 2009 a 2019 apresentados na Tabela 3, que são os reembolsáveis (145.726) e não reembolsáveis (121.737), chega-se ao total de 267.463 beneficiários. Esse valor possui uma diferença de 52.832 financiamentos se comparado com o da Tabela 2, que apresenta um total de 214.631 matrículas com financiamentos na rede Wyden.

Os dados sobre as matrículas da Wyden, mostrados neste trabalho, comprovam que o financiamento estudantil é o principal financiador dessa rede, especialmente o financiamento público por meio do FIES e do ProUni. A predominância de matrículas realizadas através do financiamento estudantil, seja público ou privado, tem contribuído para a expansão e a privatização do ensino superior privado brasileiro.

\section{Considerações Finais}

Em meio a uma crise econômica e sanitária vivenciada pelo cenário de pandemia mundial provocada pela COVID-19, que atingiu mais de 3 milhões de trabalhadores brasileiros e deixou mais de 200 mil mortos, vivemos numa constante incerteza com as pressões exercidas pelos governos para reabrir os setores econômicos, entre eles o setor educacional, em especial o privado.

Com discursos sobre uma pseudopreocupação pedagógica e sanitária, apesar da não obrigatoriedade do retorno presencial e da assistência aos estudantes que optam por algum tipo de ensino remoto (on-line), a reabertura está sendo colocada em prática, quebrando as medidas de isolamento, o que pode levar ao agravamento da contaminação pelo vírus da COVID-19.

$\mathrm{Na}$ essência, a reabertura do setor educacional está relacionada com a pressão dos grandes empresários da educação para conter os impactos negativos desse lucrativo mercado, provocados pela evasão dos estudantes e pela redução de novas matrículas. Desde que foi decretado o isolamento social para conter a disseminação da COVID-19, as IES privadas colocaram em prática um plano de ações: massificação da oferta de disciplinas na modalidade a distância; flexibilização do calendário acadêmico; política de descontos com ações para atrair e reter estudantes, planos com negociação de dívidas estudantis, demissões de professores ${ }^{4}$, entre outras, para reduzir tais impactos.

Esses impactos apresentados pelo setor privado se fizeram sentir na redução do percentual de matrículas no ano de 2020 , um cenário adverso, se comparado à expansão desse setor desde 1980. Os dados mostraram que, apesar do relativo crescimento de IES e de matrículas no setor público entre 1980 e 2019, tal expansão concentrou-se no setor privado, chegando a $88 \%$ do total das instituições e $75 \%$ do total das matrículas em 2019.

Os estudos e os dados mostram que a expansão do setor privado quanto ao número de IES e de matrículas está associada à política privatista, adotada pelo Estado, de transferências de recursos públicos para o setor privado, em detrimento do setor público. Dessas políticas, destacam-se, neste trabalho, os programas de financiamento estudantil FIES e ProUni e sua forma de contribuir para a expansão do setor privado no Brasil.

4 A Folha de São Paulo publicou, em 08 de julho de 2020, uma matéria sobre a relação do Coronavírus com o ensino remoto e a crise, em que faculdades particulares de São Paulo demitiram mais de 800 professores devido à saída de alunos e ao aumento da inadimplência durante a pandemia (PALHARES, 2020). 
Financiamento Estudantil Público e a Expansão do Ensino Superior Privado no Brasil

Evidenciou-se que, mesmo com a crise do FIES em 2015, ele continua sendo um dos principais recursos da rede Wyden. E seguindo a tendência para reduzir as consequências da diminuição do financiamento recebido pelo FIES, essa rede está investindo nos financiamentos estudantis privados, destacando-se os realizados pela própria IES e em parceria com entidades externas, a exemplo do Pravaler.

Conclui-se que o financiamento estudantil é o principal financiador da rede Wyden, especialmente o financiamento público por meio do FIES e do ProUni. Ressalta-se que o FIES é o único financiamento que prevê reembolso para o governo federal. No entanto, a obrigatoriedade do reembolso não garante que não haja incidência de inadimplência pelos seus beneficiários.

O financiamento estudantil tornou-se um dos principais mecanismos de expansão e privatização do ensino superior privado do País, especialmente de grupos empresariais ligados à financeirização do setor educacional, como é o caso da Wyden Educacional. A predominância das matrículas em IES privadas por meio da concessão de bolsas e de financiamentos, além de reduzir o arrecadamento que poderia ser investido no setor público, implica a privatização do ensino superior e o aumento do endividamento do Estado e das famílias brasileiras.

\section{Referências}

BRASIL. Constituição da República dos Estados Unidos do Brasil (de 16 de julho de 1934). Nós, os representantes do povo brasileiro, pondo a nossa confiança em Deus, reunidos em Assembleia Nacional Constituinte para organizar um regime democrático, que assegure à Nação a unidade, a liberdade, a justiça e o bem-estar social e econômico, decretamos e promulgamos a seguinte. Diário Oficial, Rio de Janeiro, 1934. Disponível em: http://www.planalto.gov.br/ccivil_03/constituicao/Constituicao34.htm. Acesso em: 7 fev. 2021.

BRASIL. Constituição dos Estados Unidos do Brasil (de 18 de setembro de 1946). Diário Oficial, Rio de Janeiro, 1946. Disponível em: http://www.planalto.gov.br/ccivil_03/Constituica o/Constituicao46.htm. Acesso em: 7 fev. 2021.

BRASIL. Constituição da República Federativa do Brasil de 1988. Diário Oficial da União, Brasília, 1988. Disponível em: http://www.planalto.gov.br/ccivil_03/Constituicao/Cons tituicao.htm. Acesso em: 7 fev. 2021.

BRASIL. Lei $n^{\circ} 8.436$, de 25 de junho de 1992. Institucionaliza o Programa de Crédito Educativo para estudantes carentes. Diário Oficial da União, Brasília, 1992. Disponível em: http://www.planalto.gov.br/ccivil_03/leis//8436.htm. Acesso em: 7 fev. 2021.

BRASIL. Lei $n^{\circ}$ 9.394, de 20 de dezembro de 1996. Estabelece as diretrizes e bases da educação nacional. Diário Oficial da União, Brasília, 1996. Disponível em: http://www. planalto.gov.br/ccivil_03/leis/19394.htm. Acesso em: 7 fev. 2021.

BRASIL. Decreto $n^{\circ} 2.306$, de 19 de agosto de 1997. Regulamenta, para o Sistema Federal de Ensino, as disposições contidas no art. 10 da Medida Provisória $n^{\circ} 1.477-39$, de 8 de agosto de 1997 , e nos arts. $16,19,20,45,46$ e $\S 1^{\circ}, 52$, parágrafo único, 54 e 88 da Lei n 9.394 , de 20 de dezembro de 1996, e dá outras providências. Diário Oficial da União, Brasília, 1997. 
Financiamento Estudantil Público e a Expansão do Ensino Superior Privado no Brasil

Disponível em: http://www.planalto.gov.br/ccivil_03/decreto/d2306.htm. Acesso em: 7 fev. 2021.

BRASIL. Medida Provisória $n^{\circ} 1.865-4$, de 26 de agosto de 1999. Dispõe sobre o Fundo de Financiamento ao Estudante do Ensino Superior e dá outras providências. Diário Oficial da União, Brasília, 1999. Disponível em: http://www.planalto.gov.br/ccivil_03/MPV/Antigas/18654.htm\#: :text=1865\%2D4\&text=MEDIDA\%20PROVIS\%C3\%93RIA\%20No\%201.865,26\%20 DE\%20AGOSTO\%20DE\%201999.\&text=Disp\%C3\%B5e\%20sobre\%20o\%20Fundo\%20de,S uperior\%20e\%20d\%C3\%A1\%20outras\%20provid\%C3\%AAncias. Acesso em: 7 fev. 2021.

BRASIL. Lei no 10.260, de 12 de julho de 2001. Dispõe sobre o Fundo de Financiamento ao estudante do Ensino Superior e dá outras providências. Diário Oficial da União, Brasília, 2001. Disponível em: http://www.planalto.gov.br/ccivil_03/leis/leis_2001/L10260compila do.htm. Acesso em: 7 fev. 2021.

BRASIL. Decreto $n^{\circ} 4.914$, de 11 de dezembro de 2003. Dispõe sobre os centros universitários de que trata o art. 11 do Decreto $n^{\circ} 3.860$, de 9 de julho de 2001, e dá outras providências. Diário Oficial da União, Brasília, 2003. Disponível em: http://www.planalto.go v.br/ccivil_03/decreto/2003/D4914.htm\#: :text=Admitir\%2Dse\%2D\%C3\%A1\%20a\%20cria\% C3\%A7\%C3\%A3o,vagas\%20definidos\%20por\%20aquele\%20Minist\%C3\%A9rio. Acesso em: 7 fev. 2021.

BRASIL. Decreto $n^{\circ} 5.622$, de 19 de dezembro de 2005. Regulamenta o art. 80 da Lei $n^{\circ}$ 9.394, de 20 de dezembro de 1996, que estabelece as diretrizes e bases da educação nacional. Diário Oficial da União, Brasília, 2005a. Disponível em: http://www.planalto.gov.br/ ccivil_03/_ato2004-2006/2005/decreto/d5622.htm. Acesso em: 7 fev. 2021.

BRASIL. Lei $n^{0} 11.096$, de 13 de janeiro de 2005. Institui o Programa Universidade para Todos - PROUNI, regula a atuação de entidades beneficentes de assistência social no ensino superior; altera a Lei $n^{\circ} 10.891$, de 9 de julho de 2004, e dá outras providências. Diário Oficial da União, Brasília, 2005b. Disponível em: http://www.planalto.gov.br/ccivil_03/_Ato20042006/2005/Lei/L11096.htm\#: :text=Institui\%20o\%20Programa\%20Universidade\%20para,20 04\%2C\%20e\%20d\%C3\%A1\%20outras\%20provid\%C3\%AAncias. Acesso em: 7 fev. 2021.

BRASIL. Lei $n^{\circ} 12.202$, de 14 de janeiro de 2010. Altera a Lei $n^{\circ} 10.260$, de 12 de julho de 2001, que dispõe sobre o Fundo de Financiamento ao Estudante do Ensino Superior - FIES (permite abatimento de saldo devedor do FIES aos profissionais do magistério público e médicos dos programas de saúde da família; utilização de débitos com o INSS como crédito do FIES pelas instituições de ensino; e dá outras providências). Diário Oficial da União, Brasília, 2010. Disponível em: http://www.planalto.gov.br/ccivil_03/_ato20072010/2010/lei//12202.htm. Acesso em: 7 fev. 2021.

BRASIL. Lei n 13.005, de 25 de junho de 2014. Aprova o Plano Nacional de Educação - PNE e dá outras providências. Diário Oficial da União, Brasília, 2014. Disponível em: http://www.planalto.gov.br/ccivil_03/_ato2011-2014/2014/lei/l13005.htm\#: :text=Aprova\% 20o\%20Plano\%20Nacional\%20de,Art. Acesso em: 7 fev. 2021.

BRASIL. Emenda Constitucional $n^{\circ}$ 95, de 15 de dezembro de 2016. Altera o Ato das Disposições Constitucionais Transitórias, para instituir o Novo Regime Fiscal, e dá outras 
Financiamento Estudantil Público e a Expansão do Ensino Superior Privado no Brasil

providências. Diário Oficial da União, Brasília, 2016. Disponível em: http://www. planalto.gov.br/ccivil_03/constituicao/emendas/emc/emc95.htm. Acesso em: 7 fev. 2021.

BRASIL. Decreto $n^{\circ}$ 9.057, de 25 de maio de 2017. Regulamenta o art. 80 da Lei $n^{\circ} 9.394$, de 20 de dezembro de 1996, que estabelece as diretrizes e bases da educação nacional. Diário Oficial da União, Brasília, 2017. Disponível em: http://www.planalto.gov.br/ccivil_03 /_Ato2015-2018/2017/Decreto/D9057.htm. Acesso em: 7 fev. 2021.

BRASIL. Instituto Nacional de Estudos e Pesquisas Educacionais Anísio Teixeira. Evolução do Ensino Superior: Graduação 1980 - 1998: Brasília: Inep, 2020a. Disponível em: https://download.inep.gov.br/download/censo/1998/superior/evolucao_1980-1998.pdf. Acesso em: 7 fev. 2021.

BRASIL. Instituto Nacional de Estudos e Pesquisas Educacionais Anísio Teixeira. Microdados Censo da Educação Superior: 1980; 1985; 1990; 1995; 2000-2005; 2009; 2010-2019. Brasília: Inep, 2020b. Disponível em: https://www.gov.br/inep/pt-br/acesso-ainformacao/dados-abertos/microdados/censo-da-educacao-superior. Acesso em: 7 fev. 2021.

BRASIL. Ministério da Educação. Fundo de Financiamento ao Estudante do Ensino Superior. Simule seu financiamento - Enfermagem. Brasília, DF: MEC, 2021. Disponível em: http://sisfiesportal.mec.gov.br/?pagina=simulacao\&no_curso=ENFERMAGEM\&semestres=1 0. Acesso em: 7 fev. 2021.

BRASIL. Receita Federal. Ministério da Economia. Centro de Estudos Tributários e Aduaneiros. Gastos Tributários - Bases Efetivas: 2006-2019. Brasília, DF: RF, ME, Cetad, 2006-2020. Disponível em: https://receita.economia.gov.br/dados/receitadata/renunciafiscal/demonstrativos-dos-gastos-tributarios/dgt-bases-efetivas. Acesso em: 7 fev. 2021.

CÂMARA DOS DEPUTADOS. Orçamento da União. Execução Orçamentária (2003-2019). Brasília, DF: Câmara dos Deputados, 2021. Disponível em: https://www2.camara.leg.br/igorcamento/. Acesso em: 7 fev. 2021.

CHAVES, Vera Lúcia Jacob. Expansão da privatização/mercantilização do Ensino Superior brasileiro: a formação dos oligopólios. Educação \& Sociedade, Campinas, v. 31, n. 111, p. 481-500, abr./jun. 2010. Disponível em: http://www.scielo.br/pdf/es/v31n111/v31n111a10.pdf. Acesso em: 7 fev. 2021.

CHAVES, Vera Lúcia Jacob; AMARAL, Nelson Cardoso. Política de expansão da Educação Superior no Brasil: o Prouni e o Fies como financiadores do setor privado. Educação em Revista, Belo Horizonte, v. 32, n. 04, p. 49-72, out./dez. 2016. Disponível em: https://www.scielo.br/scielo.php?pid=S0102-46982016000400049\&script=sci_abstract\&t Ing=pt. Acesso em: 7 fev. 2021.

CHAVES, Vera Lúcia Jacob; SANTOS, Maria Rosimary Soares dos; KATO, Fabíola Bouth Grello. Financiamento público para o Ensino Superior privado-mercantil e a financeirização. Jornal de Políticas Educacionais, v. 14, n. 08, jan. 2020. Disponível em: https://revistas.ufpr.br/jpe/article/view/70063. Acesso em: 7 fev. 2021.

GUIMARÃES, Rodrigo Gameiro. As transformações do mercado do Ensino Superior e o endividamento estudantil no Brasil: uma produção do Estado neoliberal. 2018. Tese 
Financiamento Estudantil Público e a Expansão do Ensino Superior Privado no Brasil

(Doutorado em Administração) - Escola de Administração, Universidade Federal do Rio Grande do Sul, Porto Alegre, 2018.

MANCEBO, Deise. Reforma universitária: reflexões sobre a privatização e a mercantilização do conhecimento. Educação \& Sociedade, Campinas, v. 25, n. 88, p. 845-866, out. 2004. Disponível em: https://www.scielo.br/pdf/es/v25n88/a10v2588.pdf. Acesso em: 7 fev. 2021.

PALHARES, Isabela. Com ensino remoto e crise, faculdades particulares demitem professores. Folha de S. Paulo, São Paulo, 7 jul. 2020. Disponível em: https://www1.folha. uol.com.br/educacao/2020/07/com-ensino-remoto-e-crise-faculdades-particulares-demitemprofessores.shtml. Acesso em: 7 fev. 2021.

PRAVALER. Sobre o Pravaler. Pinheiros: Pravaler, 2021. Disponível em: https://www.pravaler.com.br/sobre-o-pravaler/. Acesso em: 7 fev. 2021.

REIS, Tayanne de Fátima Almeida Tabosa dos Reis. Financiamento estudantil nas instituições privado-mercantis de Ensino Superior no Brasil: o caso da Kroton Educacional. 2019. Dissertação (Mestrado em Educação) - Instituto de Ciências da Educação, Universidade Federal do Pará, Belém, 2019.

SANTOS FILHO, João Ribeiro dos. Financiamento da Educação Superior privadomercantil: incentivos públicos e financeirização de grupos educacionais. 2016. Tese (Doutorado em Educação) - Instituto de Ciências da Educação, Universidade Federal do Pará, Belém, 2016.

SOUSA, Leila Maria Costa. Financeirização da Educação Superior privado-mercantil: implicações sobre o financiamento estudantil da Estácio Participações S.A. 2019. Dissertação (Mestrado em Educação) - Instituto de Ciências da Educação, Universidade Federal do Pará, Belém, 2019.

WYDEN EDUCACIONAL. Faculdade Área 1. Comissão Própria de Avaliação. Relatório de Autoavaliação Institucional. Salvador: Wyden, 2010. Disponível em: https://www.wyden.com.br/area1/cpa. Acesso em: 7 fev. 2021.

WYDEN EDUCACIONAL. Educação de Qualidade Internacional. Benefícios internacionais. Salvador: Wyden, 2021a. Disponível em: https://www.wyden.com.br/area1/beneficiosinternacionais. Acesso em: 7 fev. 2021.

WYDEN EDUCACIONAL. Educação de Qualidade Internacional. Faculdade Faci. Pravaler: financie com juros zero. Belém: Wyden, 2021b. Disponível em: https://www.wyden.com.br/ faci/financiamento/pravaler/pravaler-em-belem. Acesso em: 7 fev. 2021.

Samantha Castro Vieira de Souza é doutoranda em Educação pela Universidade Federal do Pará. Mestre em Educação pela Universidade Federal Fluminense, integrante do Grupo de Estudos e Pesquisas sobre Educação Superior (GEPES/UFPA) e da Rede Universitas/BR. ORCID: https://orcid.org/0000-0001-6440-2402

E-mail: samantha-souza@hotmail.com

Vera Lucia Jacob Chaves é professora titular do Instituto de Ciências da Educação da Universidade Federal do Pará. Professora do Programa de Pós-Graduação em Educação da 
Financiamento Estudantil Público e a Expansão do Ensino Superior Privado no Brasil

UFPA, pesquisadora produtividade do CNPq, Vice-coordenadora do GT-11 da ANPEd, pesquisadora da rede Universitas/ $\mathrm{Br}$ e da Rede Latino-Americana e Africana de Pesquisadores em Privatização da Educação (ReLAAPPe)

ORCID: https://orcid.org/0000-0003-3128-3659

E-mail: veraluciajacob@gmail.com

Recebido em 05 de março de 2021

Aprovado em 20 de agosto de 2021 